Global COE Hi-Stat Discussion Paper Series 131

$$
\begin{aligned}
& \text { Research Unit for Statistical } \\
& \text { and Empirical Analysis in Social Sciences (Hi-Stat) }
\end{aligned}
$$

\title{
Identity, Inequality, and Happiness: Evidence from Urban China
}

Shiqing Jiang

Ming Lu

Hiroshi Sato

March 2010 


\title{
Identity, Inequality, and Happiness:
}

\author{
Evidence from Urban China*
}

Shiqing JIANG

(Fudan University)

\author{
Ming LU \\ (Fudan University and Zhejiang University)
}

And

Hiroshi SATO

(Hitotsubashi University)

\begin{abstract}
This paper presents the impact of income inequality on the subjective wellbeing of three different social groups in urban China. We classify urban social groups according to their hukou status: rural migrants, "born” urban residents, and "acquired" urban residents who had changed their hukou identity from rural to urban. We focus on how the income disparity between migrants and urban residents affects individual happiness. The main results are as follows. People feel unhappy if inequality is related to their hukou identity, irrespective of whether they are urban residents with or without hukou. However, when identity-related inequality and other individual- and city-level characteristics are controlled, inequality measured by city-level Gini increases happiness. We also find that among urban residents who own hukou, mostly the "acquired" urban residents are unhappy with hukou-related inequality. This implies that identity is formed by both policy and personal experience. "Born” urban residents have lower happiness scores when they are old. Communist Party members strongly dislike the identity-related inequality.

Keywords: Inequality, Hukou identity, Happiness, Migration, Social integration JEL classification: I31, O15, R23

\footnotetext{
* Shiqing Jiang: Center for Industrial Development Studies, Fudan University, Shanghai 200433, E-mail: shiqing.jiang@gmail.com. Ming Lu: School of Economics, Fudan University (and Zhejiang University), Shanghai 200433, China. E-mail: lm@fudan.edu.cn. Hiroshi Sato: Graduate School of Economics, Hitotsubashi University, Tokyo 186-8601, Japan. E-mail: satohrs@econ.hit-u.ac.jp. We thank Zhao Chen, Jin Feng, Hubert Jayet, Mark Rosenzweig, Shuang Zhang, and seminar/conference participants at Fudan University and LICOS Centre for Institutions and Economic Performance, K. U. Leuven, University of Clermont-Ferrand 1, University of Lille 1, Sun Yat-sen University, and Hong Kong University of Science and Technology for their useful comments. We gratefully acknowledge financial support for the CHIP 2002 survey provided mainly by the Ford Foundation, the Swedish International Development Cooperation Agency (SIDA) and partly by the Japan Society for the Promotion of Science (JSPS) and Hitotsubashi University. Financial support from the National Social Science Project (07BJL051), the Shanghai Leading Academic Discipline Project (B101), JSPS Grants-in-Aid for Scientific Research (No. 18203018 and 21330065), the Heiwa Nakajima Foundation, and the Global COE Program "Research Unit for Statistical and Empirical Analysis in Social Sciences,” Hitotsubashi University, and "Hitotsubashi University Research Project of Policies for East Asia" is also gratefully acknowledged.
} 


\section{Introduction}

In the era of globalization, the scale of immigration is growing fast in many countries, especially developed countries in North America and Europe. In developing countries, more and more people leave their rural home heading for cities. In China, the number of rural-tourban migrants has reached $130-150$ million, and most are cross-city migrants. ${ }^{1}$ Whether the identity difference between migrants and local residents has led to inequality and unhappiness and how people respond to the identity-induced inequality are essential problems in social integration and sustainable development.

With the vast rural-to-urban labor migration, urban-rural divides have been revealed in Chinese cities as social segmentation and inequality between the urban residents who have local urban household registration (hukou) status and rural migrants who live and work in urban areas without urban hukou status. ${ }^{2}$ Although rural migrants contribute significantly to city development and are also acknowledged as the key factor in the booming of manufacturing industries, the hukou registration policy discriminates against migrants as a "floating population" and denies them equal access to social welfare programs and public services available to local urban residents. These two connected, as well as segmented, groups are forming "a dual society” in Chinese cities: migrants earn higher incomes than their rural counterparts, but under the urban-rural segmentation policy, their incomes are lower than local residents’ incomes. Such hukou-identity-induced between-group income inequality (BI,

\footnotetext{
${ }^{1}$ This is a number used in the official documents of the Chinese government.

${ }^{2}$ Regarding the fundamental role of the hukou system in the socioeconomic segmentations in China, see Liu (2005), Wang (2004), and Wu and Treiman (2007).
} 
hereafter) is also termed "horizontal inequality." The term is generally defined as the income disparity between different social groups in the same geographical area, and it is considered a more influential element than overall inequality in generating social conflict (Stewart, 2001).

How does BI affect the happiness of urban residents and their neighboring migrants? This is the core question we try to answer in this paper. We find that happiness scores are negatively correlated with hukou-identity-induced inequality (BI), irrespective of urban residents or rural migrants. However, when BI and other individual- and city-level characteristics are controlled, inequality measured by city-level Gini increases happiness. This finding implies that when studying the impact of inequality, one should distinguish income inequality between different social groups from inequality that is not induced by identity.

How do people with different hukou status respond to the between-group inequality? To answer such a question is crucial because it guides welfare analysis of who suffers from income inequality, these people being the potential proponents of institutional change for social integration in urban China. We identify three specific social groups in urban areas of China according to their hukou status. The first group is rural migrants without urban hukou status. The second group is "born” urban residents who were granted urban hukou status at birth. The third group is "acquired" urban residents who had changed their hukou status from rural to urban at some point in their life (nongzhuanfei). As Deng and Gustafsson (2006) pointed out, the "acquired” urban residents can be regarded as "permanent migrants" who have distinctive socioeconomic characteristics. We find that among urban residents with hukou, it is mainly those "acquired” urban residents who are unhappy with hukou-related 
inequality. This implies that identity is formed by both policy and personal experience. Among those "born” urban residents, Communist Party members and the elder ones strongly dislike BI.

The rest of this paper is organized as follows. Section 2 discusses studies on happiness, especially the empirical evidence from China, and studies on happiness and inequality. Section 3 describes the data. In Section 4, we use regression analysis to investigate how BI affects people with different hukou identities and characteristics, and we discuss policy implications of our findings. The final section presents the conclusions.

\section{Literature review}

The vast volume of rural-to-urban migrants is a stunning phenomenon in modern China. Rural people by now are free in deciding working in cities, and the once direct mobility control is abolished by the government. However, due to the Hukou Registration Policy, rural migrants do not have urban hukou, an institutional arrangement that entitles its owner the right to access to the urban public benefits. The lack of urban hukou makes the rural migrants suffer from discriminative policies, especially in access to public goods such as compulsory education, medicare (Zhang, 2004), labor mobility (Song, 2004), and human capital returns on the labor market (Meng and Bai, 2007; Zhang and Meng, 2007; Yan, 2007). Furthermore, through the hukou inequality arrangement, the local city government could increase the income of its residents (Chen and Lu, 2008) and their share of local public goods (Liu et al., 2009). Empirical evidence also suggests that the traditional rural-urban divide has been transformed into a segmentation between migrants and urban residents within the cities (Chen 
and Lu, 2008; Meng and Bai, 2007; Yan, 2007; Zhang and Meng, 2007). Such inequality induced by social identity is termed "horizontal inequality,"3 a between-group inequality in nature, and it is regarded as a more influential element than "vertical inequality" (for example, income Gini coefficient) in determining social conflicts and long-term growth (Stewart, 2001; Stewart et al., 2005; Stewart and Langer, 2007). We refer to the horizontal inequality as between-group inequality (BI) in the following. How does BI affect subjective wellbeing of people with different hukou status? We answer this question in this study.

Subjective wellbeing, or happiness, once a hot topic for psychologists and sociologists, is gaining attention from economists. Frey and Stutzer (2002) provided an excellent survey of happiness research. Contemporary economics literature that discusses the determinants of happiness has not clarified how social environment-like inequality affects subjective wellbeing. Most existing research focuses on the Gini coefficient as the measurement of inequality. On one hand, the ex post inequality may reflect the reward to effort, so income inequality is a symbol of economic incentives and opportunities. On the other hand, inequality may also have negative impacts, for example, reducing economic growth and increasing crime rates. Most past research has concluded that relative deprivation, or inequality, will lead to lower happiness. Alesina et al. (2004) found that the poor in America faced with income inequality do not report high happiness scores, whereas inequality reduces happiness in Europe, especially for those with leftist views. Both McBride (1998) and Luttmer (2005) find

\footnotetext{
${ }^{3}$ In her seminal paper, Stewart (2001) proposed the concept of "horizontal inequality” and defined it as “existence of severe inequalities between culturally defined groups, ..., horizontal inequalities are multidimensional—with political, economic and social elements.”
} 
that people will be unhappy when their neighbors' income increases. Graham and Felton (2005) and Rousseau (2008) find evidence that an increase in inequality diminishes individual happiness. Brockmann et al. (2008) find that life satisfaction across all income groups in China decreased between 1990 and 2000. They attribute it to the perception of worsening income distribution in China. However, in exploring determinants of happiness in rural China, Knight et al. (2009) find that happiness of rural residents is positively associated with countylevel income Gini coefficients. This can be explained using the metaphor of "the tunnel effect": when you are stuck in a tunnel and see cars in front of you move, you feel happy. In other words, with fast economic growth in China, enlarging inequality lets people have higher expectation on their own future income, so the happiness is also higher.

Regarding the disparate results in the literature, we argue that whether income inequality has negative impact on happiness is determined by the nature of the inequality. If the inequality is caused by the identity difference, larger inequality will lead to lower happiness. However, if the nature of inequality is not related to the identity, it may not cause unhappiness. To borrow the metaphor of the "tunnel effect": if the cars in all lanes are moving, you feel happy; if you are stuck in your lane (your social identity group) while cars in other lanes are moving, you feel unhappy. A lack of urban hukou limits migrants’ income prospects. Faced with lower social mobility (Wang, 2005) and hardship of gaining urban hukou status, rural migrants feel unhappy with the between-group income inequality. Even the socially advantaged group — urban residents - may suffer from the between-group income inequality, though they are in the advantageous social group. First, when BI increases, it acts as a 
negative externality upon other economic variables, thus lowering subjective wellbeing (Stewart, 2001). Second, BI can have a direct impact on happiness. Inequality is usually treated as a social evil. People naturally dislike inequality, especially when it is perceived to result from institutional discrimination, not as the economic reward from greater effort.

In sum, we expect to verify the following two hypotheses in this paper: (1) Between-group income inequality will reduce migrants' happiness. (2) When BI is controlled, the impact of general inequality on happiness is determined by the net of incentive effects and happinessreducing effects.

As more data is becoming available, the number of studies examining the determinants of happiness in China is growing. Luo (2006) explores the effects of unemployment on happiness and finds that families with unemployed members have lower happiness scores. Knight et al. (2009) examined the role of absolute and relative income on the happiness of rural Chinese residents, and their results agree with intuition: higher household income per capita results in a higher happiness level; higher relative income status within a village also leads to higher happiness. Knight and Gunatilaka (2010b) studied the happiness determination of rural migrants. They attribute the lower happiness of migrants to the changing of income reference group: their higher aspirations make them unhappier. Apart from the existing literature, our study distinguishes between-group inequality (BI) and general inequality and finds their different effects on happiness. 


\section{Data description}

Data used in our research are from an urban household survey and a migrant household survey, which are included in the 2002 Chinese Household Income Project Survey (CHIP2002), a database collected by the Chinese Academy of Social Science. The data include a series of individual and household characteristics and information on income. More importantly, there are attitude questions on "happiness" for the head or a main member of the household. ${ }^{4}$ The urban survey was conducted in 62 cities, but the migrant household survey was conducted in only 27 cities. Finally, we do not include the observations of Honghe Minority Autonomy State, because we lack its city-level variables from China City Statistical Yearbook. Since the focus of this paper is city-level inequality, we need to control other citylevel variables to alleviate the missing variable bias. ${ }^{5}$ Thus, we only use the 26 matched cities in our subsample.

The dependent variable, which is the key variable in our analysis, is the subjective happiness score of the household respondent. One of the adults in each sampled household was asked the same question: “Generally speaking, how happy do you feel?” The six possible answers were very happy, happy, so-so, not happy, not happy at all, and don’t know. We do not include the observations with the answer "don't know” and rate the other five answers as 4, 3, 2, 1, and 0, respectively. We mainly use ordinary least squared (OLS) regression in our analysis. The reasons are twofold: first, Ferrer-i-Carbonell and Frijters (2004) found that in a

\footnotetext{
${ }^{4}$ For details of the sampling framework and sampling method of the CHIP 2002 survey, see Gustafsson et al. (2008).

${ }^{5}$ Actually, in those regressions without controlling city-level variables, whether or not the samples of Honghe are included does not alter the results.
} 
happiness function, the significance and sign of coefficients are robust for either OLS or ordered probit/logit. OLS regression is more intuitive and interpretable by readers. The second reason is that we control the interaction terms in our regression, and it is difficult to interpret the marginal effects of the interacted variables when using ordered probit/logit. Knight et al. (2009) and Knight and Gunatilaka (2010a, 2010b) also used OLS to explore happiness determination in China. Of course, we also estimated ordered probit models and found that ordered probit models and the corresponding OLS results are consistent in terms of the signs and significance of the coefficients. Therefore, we choose OLS, which is more intuitive and easier to interpret. ${ }^{6}$

The independent variables are structured as follows. First, we classify an individual's hukou identity using a dummy variable with a value of 1 if she/he has urban hukou status and 0 if she/he has rural hukou status. ${ }^{7}$ Second, as the measure of BI, we utilize the income gap of urban residents and migrants calculated as the ratio between the mean incomes of each hukou identity group. This variable is regarded as a monetary measure of the socioeconomic gap generated by the hukou status combined with other discriminatory urban-rural segmentation policies. Here, for urban residents, income includes wages, bonus, allowance, subsidy for minimum living standard, living hardship subsidies from work unit, second job and sideline income, and monetary value of income in kind; for the rural migrants, income includes wages, revenues from family production, income from assets, cash gifts, and other income. We also add an interaction term between BI and hukou identity to examine the effect of income

\footnotetext{
${ }^{6}$ To save space, the ordered probit results are not reported, but they are available upon request.

${ }^{7}$ We do not include those $1.71 \%$ samples from urban survey data who report their hukou status as "rural."
} 
inequality on each group. Third, we also calculate the Gini coefficient for each city as a measurement of overall inequality that is different from identity-related inequality. Fourth, following previous studies that found that expectation of future income was a statistically significant factor in current happiness (Luo, 2006; Knight and Gunatilaka, 2010b), we introduce a dummy variable that indicates respondents' expectations for income change over the next five years: "big increase," "small increase," "unchanged," or “decrease” ("unchanged" is the base group). Fifth, we employ the log of annual household income per capita in order to control the influence of the absolute level of household income.

Other controlled variables include sex, age, age squared, years of schooling completed, health condition, marital status, political identity (member of Chinese Communist Party or not), employment status (employed or not), and household living arrangements in square meters per capita.

Appendix Tables 1 and 2 provide variable definitions and statistical descriptions. Appendix Table 1 presents the descriptions of between-group inequality and city-level Gini for the 26 cities. Figure 1 shows a significant positive correlation between BI and city-level Gini. In order to more closely see the role of BI on general inequality, we apply the entropy index (with parameters $0,1,2$ ) to decompose inequality into between-group (identity-induced inequality) and within-group inequality. From Appendix Table 2, we can see that the hukouidentity-induced inequality can explain $12.82-18.46 \%$ of total inequality, and the Theil index decomposition shows the amount of between-group inequality to be $17.59 \%$. Therefore, $\mathrm{BI}$ is an important source of inequality. Appendix Table 3 gives the characteristics of migrants and 
urban residents. The last column is the p-value for the ANOVA test of equal means. From the table, we can see that migrants and urban residents are two distinct groups of people: urban residents have higher happiness scores, and they have higher education levels and household incomes than migrants; migrants are overwhelmingly male and are also younger, healthier, and more optimistic about future income change.

\section{Regression results}

\subsection{Hukou, between-group inequality, and happiness}

We first examine how between-group inequality affects the happiness of urban residents and migrants. We establish the following happiness functions:

$$
\text { Happiness }_{i j}=a_{0}+\alpha_{1} \cdot \text { Hukou }_{i j}+\alpha_{2} \cdot B I_{j}+\alpha_{3} \cdot \text { Hukou }_{i j} \times B I_{j}+\beta \cdot X_{i j}+\gamma \cdot Z_{j}+\varepsilon_{i j}
$$

$B I_{j}$ is the between-group inequality. Subscripts $i$ and $j$ denote the individual and city, respectively. We also add interaction terms between $H u k o u_{i j}$ and $B I_{j}$ to examine whether urban residents and migrants have different attitudes toward BI. $X_{i j}$ includes the individuallevel characteristics, and $Z_{j}$ is a vector of city-level controls. Regression results are in Table 1.

\section{[Table 1 about here]}

We report four regression results in Table 1. In column 1, we do not control hukou dummy variables and the interaction terms between BI and hukou, whereas column 2 includes them. The problem with column 2 regression is its potential missing-variable bias. The focus of the regressions is the coefficient of $\mathrm{BI}$, but it is somehow correlated with education difference. So 
in column 3 we add the ratio of the average education level of urban residents to that of migrants. Equation 4 controls more city-level variables to alleviate the missing-variable bias.

What we are primarily concerned with is the coefficient of BI. All of the four regressions find that if inequality is related to identity, it reduces happiness, and that, in contrast, the overall inequality means hope for becoming rich and brings happiness, when the identityinduced BI has been controlled. The reason why BI reduces happiness for both urban residents and migrants is twofold. On one hand, when BI is higher, it is more difficult for people with lower social status to become rich. On the other hand, BI has so strong a negative externality that even urban residents with hukou will feel unhappy. This may be explained by the social unrest and crime caused by identity-induced inequality. As BI exists partly because of educational differences between urban residents and migrants, we control the ratio of the average education level of urban residents' to that of migrants in equation 3 . The result does not show significant changes in the coefficient of BI. We also want to check whether BI is correlated with missing city characteristics. So we add several city-level variables, including per capita GDP, population growth, whether the city is big, ${ }^{8}$ and dummies for cities located in the middle or west of China. Equation 4 shows a greater absolute value of the coefficient of BI. This means the coefficient of BI tends to be biased toward 0 if the city-level variables are omitted.

Rather surprisingly, after controlling BI, the city-level Gini coefficient is significantly positive. Interestingly, Knight et al. (2009) also found a significantly positive county-level

\footnotetext{
${ }^{8}$ The criterion of defining a big city is whether it had more than 1.5 million non-agricultural population in 1990.
} 
Gini for happiness when they explored the happiness determination of rural Chinese residents. Our explanation is similar to that of Knight et al (2009).: in an era of rapidly increasing incomes, people may optimistically expect their future opportunities to be at the higher end of the income distribution (demonstration effect). When we control more city-level variables in equation 4, Gini coefficient has a greater effect of increasing happiness. This indicates that the effect of overall inequality on happiness is underestimated without controlling city-level variables. However, the population ratio between migrants and urban residents in our sample differs from the one in the real world, so the calculated city-level Gini may only be taken as a proxy of the real Gini.

The Hukou dummy and its interaction term with BI are not significant in equation 2. In other words, compared with migrants, an average urban resident does not show a significantly different attitude toward BI. We surmise that this is because we have not considered the heterogeneity among urban residents and their different aversions to BI. This heterogeneity will be studied in the next section.

All the other coefficients in our study are consistent with findings in previous studies (Luo, 2006; Knight et al., 2009; Knight and Gunatilaka, 2010a, 2010b). The results also show that the Chinese people are somehow unique in happiness formation. Compared with females, males have lower happiness scores, possibly because they shoulder more responsibility in society and face more stress. This finding is different from those in Western countries, where males are happier (for example, Graham and Felton, 2005, a study on Latin America). Age has a U-shaped effect on happiness, with a turning point at age 39.3 in column 4. Middle-aged 
people shoulder more responsibility for their family and job, so they have the lowest happiness score. Marital status influences happiness: compared with unmarried people, married people can enjoy a family life, and thus, they have higher happiness scores, but divorce or being widowed significantly reduces happiness. This implies that marriage is like gambling. If the probability of divorce is greater than $46.6 \%$, single people lead a happier life than married people. Educational attainment has an insignificant effect on happiness. The same findings are in Luo (2006), who used dummy variables for education level based on CHIPS data and found that all levels of education had an insignificant effect on happiness. Generally, education increases happiness, but in China, the effect of education could have been seen through other variables like income. Therefore, when variables like income have been controlled, education does not have independent channels to affect happiness.

Other findings are easy to interpret and consistent with existing literature. Unemployment significantly reduces happiness. This intuitive result is consistent with earlier literature (Winkelmann and Winkelmann, 1998). The log yearly household per capita income has a significant positive effect on happiness, even if relative income is controlled. The semielasticity of income is about 0.27 and is close to the estimation of Knight and Gunatilaka (2010b). Political identity, measured as whether the individual is a Communist Party member, significantly increases happiness, perhaps because party membership may bring more political or social capital. Previous studies have confirmed that Party identity brings higher income (Appleton et al., 2005; Knight and Yueh, 2002; Li, Lu and Sato, 2009); however, even when we control the log household income, Party identity still leads to greater happiness 
because of non-monetary benefits. People who optimistically expect that they will have a big or small increase in income after five years are much happier, and big expectations lead to 3 times the increase in happiness scores than small expectations. Pessimistic expectations for future income lead to lower happiness. The coefficients on self-reported health also agree with intuition: people who say they are in good health are happier than those reporting health as so-so, and self-reported bad health significantly reduces happiness.

The effects of city-level variables on happiness are also interesting. We control the ratio of education level between urban residents and migrants. We find that without controlling this, the coefficient of identity-related inequality is biased toward 0. Besides, the education difference itself reduces happiness of both urban residents and migrants. To alleviate missingvariable bias further, we add city-level economic, population, and geography controls to the right hand side of equation 4. Per capita GDP shows an insignificantly positive effect on happiness. In urban China, the rapid growth of urban population is mainly due to influx of rural migrants who do not have local hukou. However, since the size of public resources in cities is allocated according to hukou population, so when population growth is high, people may face congestion problems in public service and feel unhappy. We try to control the compound yearly growth of non-agricultural population of each city during 1998 to $2002 .^{9}$ Happiness is found to be significantly and negatively correlated with growth rate in a city’s non-agricultural population. However, we cannot argue against migration and city expansion, as city expansion also leads to scale economy in economic growth and improvement in

\footnotetext{
${ }^{9}$ The population growth of Pinliang City of Gansu Province is for the period 2002-2004, because of incomplete data.
} 
quality of life. We do find that people are happier in the big cities we have identified in our research. In summary, equation 4 suggests that city scale is positively correlated with happiness, but if a city expands too fast, people will feel unhappy. In other words, a city needs policies to alleviate congestion effects to meet the need of city expansion.

Is the coefficient of $\mathrm{BI}$ also economically significant? We compare the magnitude of coefficients of BI with other variables. Consider column 4 in Table 1 . Note that when the income ratio between urban residents and migrants is reduced by 1 , its effect on happiness is the same as if per capita household income had increased $53.2 \%$. That is 5 years of income growth for urban residents with a 9\% annual growth rate of per capita income or 7.6 years of income growth for rural residents at an annual growth rate of $6 \%$. Looking at other variables, reducing the urban-migrant income ratio by 1 has the same effect on happiness as increasing per capita living space by 29.9 square meters.

\subsection{Heterogeneity of urban residents, between-group inequality, and happiness}

In Table 1, hukou and its interaction term with BI are both insignificant. Intuitively, urban residents should have shown higher happiness compared with migrants, because they are the advantageous social group under the hukou system. We surmise the interaction term between hukou and BI is insignificant because we did not consider the heterogeneous hukou identity among urban residents.

Although the hukou policy has lasted for a long time, it is still possible to change rural hukou to urban hukou by attending college, becoming a government official, joining the army, 
losing land to the government, buying a house in a city, or even buying a hukou. How does a changed hukou status affect attitudes toward BI? Will the once rural hukou owners assimilate among the "born" urban hukou residents if the duration of their urban stay is long enough? These two questions need to be explored. If the once rural hukou residents are averse to BI yet their attitudes are not assimilated, they will be potential voters for social integration policy in the future. Accordingly, our questionnaire further differentiates urban hukou into two new categories, with "born” urban hukou as 1 for those who have never changed their hukou status, and "acquired" urban hukou as 1 for people who used to be rural residents but acquired urban hukou status later in life. The reference group is still the rural migrants. The interaction terms between "born," "acquired” urban hukou, and BI are used to see whether these two groups have similar attitudes to inequality compared with migrants. We also interact the interaction terms of "acquired" urban hukou and BI with years since getting hukou to check whether “acquired" urban hukou residents assimilate with the "born” urban residents. The regression results are in Table 2.

\section{[Table 2 about here]}

We discuss the three cases of hukou status. First, consider the results in Table 2, column 5.

Like the results in Table 1, migrants show aversion to BI (with a marginal effect of -0.125 ). The BI also has negative effect on the happiness scores for "born” urban residents, however, their advantageous social status alleviate the negative impacts on happiness scores. The marginal effect of BI for "born” urban residents is quite small $(-0.125+0.0803=-0.0447)$. 
This implies that even with a small startup cost, the "born" urban residents may not advocate social integration policy. Furthermore, even if the "born" urban dummy has a negative coefficient, it does not mean they are unhappier than migrants. When BI is greater than 2.7, their high social status will make them happier than migrants. In our sample, city-level BI is between 1.12 and 3.47. Only when BI is small, those "born” urban residents are not socially powerful enough and face competition from migrants, so they will be unhappier.

The most striking result here pertains to the "acquired" urban hukou residents: they have insignificantly different attitudes toward BI compared with migrants - that is, they say they suffer from unhappiness when the income gap increases, but they do not show greater happiness because of their urban hukou. This finding further explains why the interaction term between hukou and BI is not significant in Table 1. It is largely because the "acquired" urban hukou residents account for $22.4 \%$ in our urban sample, and they do not show different attitudes to BI compared with migrants. Furthermore, this also implies that identity formation is not only related to policy but also to one's experience and his/her self-identity. Because the urban public policy in China is mainly determined by the urban residents (there are no "voting” rights for the people who do not secure a local urban hukou), the "acquired" urban hukou residents are actually the "spokespersons” for migrants. However, the sample statistics in our data show that they are still in the minority among the urban residents and not influential enough to abolish rural-urban segmentation policy.

As the attitudes of "acquired” urban hukou residents are closer to those of migrants, do they change their aversion of BI as they live longer in cities? In equation 6, we add an 
interaction term between "years since getting hukou" and "acquired urban hukou $\times$ BI." We want to examine whether with a longer urban stay, "acquired" urban hukou residents assimilate to the "born" urban residents. If so, the new interaction term would at least be significant. However, we found it to be insignificant. Therefore, it is reasonable to conclude that formal rural life experiences have a persistent effect on perceptions of BI.

Being aware that $\mathrm{BI}$ is partly attributed to educational differences, we control the education ratio in equations 7 and 8 . In this case, the magnitude of $\mathrm{BI}$ is even greater. In other words, the effect of BI on happiness is underestimated if the education difference is omitted. Besides, when the education ratio is controlled, the interaction term between "born" urban residents and $\mathrm{BI}$ also becomes insignificant. This implies that $\mathrm{BI}$ induced not by educational difference but by discrimination strongly diminishes happiness, and people with different hukou identity do not show different attitudes to discrimination-related BI.

\subsection{Different attitudes among “born” urban hukou residents toward between-group inequality}

An increasingly important problem in China is how to reduce the income gap between rural and urban China, which reached 3.33 to 1 by the end of year 2007, the highest in the 30 years of reform since the opening up of China. ${ }^{10}$ What is worrying, with more and more migrants in Chinese cities, is that the traditional rural-urban divide has gradually become a divide between migrants and urban residents. Meng and Bai (2007) found that during 20002004, wage increases for migrants stagnated in Guangdong Province. Both Yan (2007) and

\footnotetext{
${ }^{10}$ Source of data: NBS, China Statistical Yearbook 2008, China Statistical Press, 2008.
} 
Zhang and Meng (2007) found that the income gap between migrants and urban residents is still widening because of different returns on human capital. Social integration policies are urgently needed for China's urbanization and economic growth (Chen and Lu, 2008). Although we have shown that those "born” urban hukou residents are also unhappy with BI, the magnitude is small. So they would not strongly advocate social integration policies faced with costs of action. The "acquired” urban hukou residents are averse to BI, but they account for less than 1/4 of urban hukou residents, whereas migrants do not have formal channel of voice in urban policy making. Therefore, we still need to elaborate upon the attitude of "born" urban residents toward BI. By doing so, the focus here is to check whether people with certain characteristics will be more averse to inequality. Specifically, we added a series of interaction terms between individual characteristics and BI into the regression. Table 3 reports the results.

\section{[Table 3 about here]}

In column 9 of Table 3, we add an interaction term between age and BI. This term has a significant negative sign, which indicates that older people dislike BI more. In column 10, we add interaction of interact Communist Party membership with BI. We find that Party members strongly dislike BI (with a coefficient of -0.108). It is not a surprising result, because Party members are drawn from the elite of Chinese society, and they may have a strong taste for social justice and a much deeper understanding of the harm of BI.

In columns 11-13, we add interaction terms of years of schooling, log household income per capita, and gender, respectively, with BI, but neither is significant. Thus, we conclude that 
"born” urban hukou residents have similar views toward BI regardless of differences in education, household income, and gender.

\section{Conclusion}

In modern economics literature concerning the determinants of happiness, how social environment such as inequality affects subjective wellbeing is still unclear. In this paper, we focused on how income inequality, specifically the inequality between urban residents and migrants, affects happiness. Our main empirical result is: People feel unhappy if inequality is related to their hukou identity, irrespective of whether they are urban residents with or without hukou. However, when identity-related inequality and other individual- and city-level characteristics are controlled, inequality measured by city-level Gini increases happiness. This finding suggests that social unrest is caused by inequality induced by identity and between groups with different social identity, but not inequality that might work as an incentive for the society. We also find that among urban residents with hukou, primarily the "acquired" urban residents are unhappy with hukou-related inequality. This implies that identity is formed by both policy and personal experience. The older "born” urban residents have lower happiness scores. Communist Party members strongly dislike the identity-related inequality.

Our empirical results contain strong policy implications. In the era of globalization and urbanization, many people migrate across borders of countries or regions and from rural to urban settings. For a society with identity-based social segmentation-for example, in developed countries with many immigrants — and for developing countries like China with 
large-scale rural-to-urban migrants, social integration and narrowing identity-based inequality are urgent for sustainable economic and social development. In China, the potential proponents of social integration policy will be those who are most sensitive to income inequality induced by hukou identity: migrants who have no voice in local public policy as yet; "acquired” urban residents who somewhat preserve rural characteristics; Communist Party members; and elderly people among “born” urban residents. 


\section{References}

Alesina, Alberto, Rafael Di Tella, and Robert MacCulloch, 2004. "Inequality and happiness: Are Europeans and Americans different?” Journal of Public Economics, 88 (9-10), 2009-2042.

Appleton, Simon, Lina Song, and Qingjie Xia, 2005. "Has China Crossed the River? The Evolution of Wage Structure in Urban China during Reform and Retrenchment.” Journal of Comparative Economics, 33, 644-663.

Chen, Zhao and Ming Lu, 2008. “From Segmentation to Integration: The Political Economy of Urban-Rural Economic Growth and Social Harmony.” Economic Research Journal, 2008-1, 21-32 (in Chinese).

Deng, Quheng and Björn Gustafsson. 2006. “China’s Lesser Known Migrants.” IZA Discussion Paper, 2152, 1-49.

Ferrer-i-Carbonell, Ada and Paul Frijters, 2004. “How Important is Methodology for the Estimates of the Determinants of Happiness.” Economic Journal, 114 (497), 641-659.

Frey, Bruno S. and Alois Stutzer, 2002. "What Can Economists Learn from Happiness Research?” Journal of Economic Literature, XL (2), 402-435.

Gustafsson, Björn, Shi Li, and Terry Sicular (eds.), 2008. Inequality and Public Policy in China, New York: Cambridge University Press.

Knight, John and Ramani Gunatilaka, 2010a. “Great Expectations? The Subjective Wellbeing of Rural-Urban Migrants in China.” World Development, 38(1), 113-124 
Knight, John and Ramani Gunatilaka, 2010b. “Aspirations, Adaptation and Subjective Wellbeing of Rural-Urban Migrants in China.” forthcoming in Journal of Development Studies.

Knight, John, Lina Song and Ramani Gunatilaka, 2009. “Subjective Well-being and Its Determinants in Rural China.” China Economic Review Volume 20, Issue 4, December 2009, Pages 635-649.

Knight, John. and Linda Yueh, 2008. "The Role of Social Capital in the Labour Market in China.” Economics of Transition, 16(3), 389-414.

Li, Shuang, Ming Lu, Hiroshi Sato, 2009. "Power as a Driving Force of Inequality in China: How Do Party Membership and Social Networks Affect Pay in Different Ownership Sectors?” CESifo Economic Studies, 55(3-4), 624-647.

Liu, Zhiqiang, 2005. “Institution and inequality: the hukou system in China.” Journal of Comparative Economics, 33(1), 133-157.

Luo, Chuliang, 2006. “Urban-Rural Division, Employment Status and Subjective Wellbeing.” China Economic Quarterly, 2, 188-211 (in Chinese).

Meng, Xin and Nansheng Bai, 2007. "How Much Have the Wages of Unskilled Workers in China Increased: Data from Seven Factories in Guangdong.” in Ross Garnaut and Ligang Song (eds.), China: Linking Markets for Growth, Asia Pacific Press, 151-175. Stewart, Frances, 2001. “Horizontal Inequalities: A Neglected Dimension of Development.” UNU World Institute for Development Economics Research Working Paper. 
Stewart, Frances, Graham Brown, and Luca Mancini, 2005, "Why Horizontal Inequalities Matter: Some Implications for Measurement,” CRISE Working Paper No. 19.

Stewart, Frances and Arnim Langer, 2007, “Horizontal Inequalities: Explaining Persistence and Change,” CRISE Working Paper No. 39.

Wang, Fei-Ling, 2004. “Reformed Migration Control and New Targeted People: China’s Hukou System in the 2000s.” The China Quarterly, 177, 115-132.

Wu, Xiaogang, and Donald J. Treiman, 2007. “Inequality and Equality Under Chinese Socialism: The Hukou System and Intergenerational Occupational Mobility.” American Journal of Sociology, 113, 415-445.

Yan, Shanping, 2007. “Human Capital, Institution and Wage Differences: Empirical Evidences of Dual Labor Market in Mega Chinese Cities.” Management World, 6, 4-14 (in Chinese).

Zhang, Dandan, and Xin Meng, 2007. “Assimilation or Disassimilation?: The Labour Market Performance of Rural Migrants in Chinese Cities,” paper presented at the 6th Conference on Chinese Economy, CERDI-IDREC, Clermont-Ferrand, France, Oct. 1819. 
Table 1

Happiness functions of urban residents and migrants

Dependent variable: cardinal happiness scores; regression method: OLS

\begin{tabular}{|c|c|c|c|c|c|}
\hline \multicolumn{2}{|l|}{ 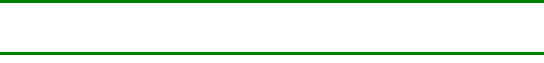 } & (1) & (2) & (3) & (4) \\
\hline \multirow{2}{*}{\multicolumn{2}{|c|}{$\mathrm{BI}$}} & $-0.0592 * * *$ & $-0.0912 * *$ & $-0.0959 * * *$ & $-0.143 * * *$ \\
\hline & & $(0.0208)$ & $(0.0366)$ & $(0.0365)$ & (0.0398) \\
\hline \multirow{2}{*}{\multicolumn{2}{|c|}{ Gini }} & $1.451^{* * *}$ & $1.441 * * *$ & $1.489 * * *$ & $2.764 * * *$ \\
\hline & & $(0.314)$ & $(0.314)$ & $(0.316)$ & $(0.429)$ \\
\hline \multirow{2}{*}{\multicolumn{2}{|c|}{ Hukou $\times$ BI }} & & 0.0482 & 0.0442 & 0.0491 \\
\hline & & & $(0.0432)$ & $(0.0433)$ & $(0.0432)$ \\
\hline \multirow{2}{*}{\multicolumn{2}{|c|}{ Hukou }} & & -0.122 & -0.113 & -0.138 \\
\hline & & & (0.0859) & $(0.0863)$ & $(0.0861)$ \\
\hline \multirow{2}{*}{\multicolumn{2}{|c|}{ Male }} & $-0.0603 * * *$ & $-0.0647 * * *$ & $-0.0651^{* * *}$ & $-0.0626^{* * *}$ \\
\hline & & $(0.0222)$ & $(0.0226)$ & $(0.0226)$ & $(0.0225)$ \\
\hline \multirow{2}{*}{\multicolumn{2}{|c|}{ Age }} & $-0.0236^{* * *}$ & $-0.0225^{* * *}$ & $-0.0221^{* * *}$ & $-0.0232 * * *$ \\
\hline & & $(0.00617)$ & $(0.00635)$ & $(0.00636)$ & $(0.00632)$ \\
\hline \multirow{2}{*}{\multicolumn{2}{|c|}{ Age squared }} & $0.000301^{* * *}$ & $0.000294 * * *$ & $0.000290 * * *$ & $0.000295^{* * *}$ \\
\hline & & $(0.0000638)$ & $(0.0000649)$ & $(0.0000649)$ & $(0.0000645)$ \\
\hline \multirow[t]{6}{*}{ Marital status: } & Married & $0.105^{*}$ & 0.0948 & 0.0985* & $0.116^{* *}$ \\
\hline & & $(0.0578)$ & $(0.0580)$ & $(0.0580)$ & $(0.0576)$ \\
\hline & Divorced & $-0.256^{* *}$ & $-0.264^{* *}$ & $-0.260 * *$ & $-0.249 * *$ \\
\hline & & $(0.109)$ & $(0.110)$ & $(0.110)$ & (0.109) \\
\hline & Widowed & $-0.195^{*}$ & $-0.205^{*}$ & $-0.199 *$ & -0.174 \\
\hline & & $(0.106)$ & $(0.107)$ & $(0.107)$ & $(0.106)$ \\
\hline \multirow{2}{*}{\multicolumn{2}{|c|}{ Years of schooling completed }} & 0.00188 & 0.00345 & 0.00336 & 0.00328 \\
\hline & & $(0.00367)$ & $(0.00391)$ & $(0.00391)$ & $(0.00389)$ \\
\hline \multirow[t]{4}{*}{ Health: } & Good & $0.218 * * *$ & $0.215^{* * *}$ & $0.215^{* * *}$ & $0.210 * * *$ \\
\hline & & $(0.0253)$ & $(0.0256)$ & $(0.0256)$ & $(0.0256)$ \\
\hline & Bad & $-0.165^{* * *}$ & $-0.164 * * *$ & $-0.164^{* * *}$ & $-0.173 * * *$ \\
\hline & & $(0.0545)$ & $(0.0545)$ & $(0.0545)$ & $(0.0540)$ \\
\hline \multirow{2}{*}{\multicolumn{2}{|c|}{ Communist Party member }} & $0.0698 * * *$ & $0.0713^{* * *}$ & $0.0725^{* * *}$ & $0.0707 * * *$ \\
\hline & & $(0.0269)$ & $(0.0270)$ & $(0.0270)$ & $(0.0269)$ \\
\hline \multirow{2}{*}{\multicolumn{2}{|c|}{ Unemployed }} & $-0.186 * * *$ & $-0.179 * *$ & $-0.181^{* *}$ & $-0.184^{* * *}$ \\
\hline & & $(0.0713)$ & $(0.0718)$ & $(0.0717)$ & $(0.0710)$ \\
\hline \multirow{2}{*}{\multicolumn{2}{|c|}{ Log household income per capita }} & $0.257 * * *$ & $0.256^{* * *}$ & $0.254^{* * *}$ & $0.269 * * *$ \\
\hline & & $(0.0185)$ & $(0.0194)$ & $(0.0194)$ & $(0.0209)$ \\
\hline \multirow{2}{*}{\multicolumn{2}{|c|}{ Expect big income increase }} & $0.326 * * *$ & $0.325^{* * *}$ & $0.323^{* * *}$ & $0.320 * * *$ \\
\hline & & $(0.0616)$ & $(0.0618)$ & $(0.0617)$ & $(0.0622)$ \\
\hline \multirow{2}{*}{\multicolumn{2}{|c|}{ Expect small income increase }} & $0.110^{* * *}$ & $0.109 * * *$ & $0.110^{* * *}$ & $0.111^{* * *}$ \\
\hline & & $(0.0238)$ & $(0.0238)$ & $(0.0238)$ & $(0.0238)$ \\
\hline \multirow{2}{*}{\multicolumn{2}{|c|}{ Expect income decrease }} & $-0.364 * * *$ & $-0.363 * * *$ & $-0.362 * * *$ & $-0.357 * * *$ \\
\hline & & $(0.0344)$ & $(0.0345)$ & $(0.0345)$ & $(0.0343)$ \\
\hline \multicolumn{2}{|c|}{ Square meters of housing per capita } & $0.00418 * * *$ & $0.00444 * * *$ & $0.00442 * * *$ & $0.00478^{* * *}$ \\
\hline
\end{tabular}




\begin{tabular}{|c|c|c|c|c|}
\hline & $(0.00123)$ & $(0.00123)$ & $(0.00123)$ & $(0.00125)$ \\
\hline Education ratio & & & $\begin{array}{l}-0.116^{*} \\
(0.0699)\end{array}$ & $\begin{array}{l}-0.262^{* * *} \\
(0.0771)\end{array}$ \\
\hline GDP per capita & & & & $\begin{array}{l}0.00000380 \\
(0.00000525)\end{array}$ \\
\hline Population growth & & & & $\begin{array}{l}-3.930 * * * \\
(0.827)\end{array}$ \\
\hline Big city & & & & $\begin{array}{l}0.101^{* * *} \\
(0.0291)\end{array}$ \\
\hline Middle & & & & $\begin{array}{l}0.0380 \\
(0.0362)\end{array}$ \\
\hline West & & & & $\begin{array}{l}-0.0466 \\
(0.0430)\end{array}$ \\
\hline Constant & $\begin{array}{l}-0.0453 \\
(0.228)\end{array}$ & $\begin{array}{l}0.00957 \\
(0.258)\end{array}$ & $\begin{array}{l}0.171 \\
(0.273)\end{array}$ & $\begin{array}{l}0.00541 \\
(0.275)\end{array}$ \\
\hline Number of observations & 5630 & 5630 & 5630 & 5630 \\
\hline R-squared & 0.145 & 0.145 & 0.146 & 0.152 \\
\hline
\end{tabular}

Note: *, **, ***: Coefficient different from zero at $10 \%, 5 \%, 1 \%$ significance levels, respectively. Robust standard errors are in parentheses. 
Table 2

Happiness functions of "born” and "acquired” urban residents and migrants

Dependent variable: cardinal happiness scores; regression method: OLS

\begin{tabular}{|c|c|c|c|c|}
\hline & (5) & (6) & (7) & (8) \\
\hline \multirow[t]{2}{*}{ BI } & $-0.125^{* * *}$ & $-0.127 * * *$ & $-0.140 * * *$ & $-0.145 * * *$ \\
\hline & $(0.0398)$ & $(0.0413)$ & $(0.0398)$ & $(0.0415)$ \\
\hline \multirow[t]{2}{*}{ Gini } & $2.589 * * *$ & $2.646 * * *$ & $2.817 * * *$ & $2.898 * * *$ \\
\hline & $(0.422)$ & $(0.436)$ & $(0.429)$ & $(0.445)$ \\
\hline \multirow[t]{2}{*}{ “Born” urban } & $-0.217 * *$ & $-0.220 * *$ & $-0.197 * *$ & $-0.203^{* *}$ \\
\hline & $(0.0912)$ & $(0.0933)$ & $(0.0915)$ & $(0.0935)$ \\
\hline \multirow[t]{2}{*}{ “Acquired” urban } & 0.00855 & 0.00797 & 0.0120 & 0.00896 \\
\hline & $(0.113)$ & $(0.114)$ & $(0.113)$ & $(0.114)$ \\
\hline \multirow[t]{2}{*}{ “Born” urban $\times$ BI } & $0.0803 *$ & $0.0807 *$ & 0.0692 & 0.0718 \\
\hline & $(0.0457)$ & $(0.0469)$ & $(0.0458)$ & $(0.0470)$ \\
\hline \multirow[t]{2}{*}{ "Acquired" urban × BI } & 0.00105 & -0.0377 & -0.00192 & -0.0381 \\
\hline & $(0.0565)$ & $(0.0653)$ & $(0.0564)$ & $(0.0650)$ \\
\hline \multirow{2}{*}{$\begin{array}{l}\text { "Acquired" urban } \times \mathrm{BI} \times \text { years } \\
\text { since getting urban hukou }\end{array}$} & & 0.00136 & & 0.00134 \\
\hline & & $(0.00102)$ & & $(0.00102)$ \\
\hline \multirow[t]{2}{*}{ Education ratio } & & & $-0.256^{* * *}$ & $-0.256^{* * *}$ \\
\hline & & & $(0.0771)$ & $(0.0779)$ \\
\hline \multirow[t]{2}{*}{ GDP per capita } & 0.00000757 & 0.00000742 & 0.00000610 & 0.00000603 \\
\hline & $(0.00000528)$ & $(0.00000540)$ & $(0.00000531)$ & $(0.00000543)$ \\
\hline \multirow[t]{2}{*}{ Population growth } & $-4.096^{* * *}$ & $-4.090 * * *$ & $-4.386 * * *$ & $-4.400 * * *$ \\
\hline & $(0.838)$ & $(0.852)$ & $(0.843)$ & $(0.858)$ \\
\hline \multirow[t]{2}{*}{ Big city } & $0.0887^{* * *}$ & $0.0861 * * *$ & $0.110^{* * *}$ & $0.109 * * *$ \\
\hline & $(0.0286)$ & $(0.0292)$ & $(0.0293)$ & $(0.0299)$ \\
\hline \multirow[t]{2}{*}{ Middle } & 0.0211 & 0.0196 & 0.0391 & 0.0375 \\
\hline & $(0.0358)$ & $(0.0363)$ & $(0.0363)$ & $(0.0369)$ \\
\hline \multirow[t]{2}{*}{ West } & -0.0537 & -0.0534 & -0.0433 & -0.0436 \\
\hline & $(0.0432)$ & $(0.0437)$ & $(0.0432)$ & $(0.0437)$ \\
\hline \multirow[t]{2}{*}{ Constant } & -0.343 & -0.350 & -0.0581 & -0.0688 \\
\hline & $(0.267)$ & $(0.272)$ & $(0.276)$ & $(0.280)$ \\
\hline Individual characteristics & Yes & Yes & Yes & Yes \\
\hline Number of observations & 5630 & 5478 & 5630 & 5478 \\
\hline R-squared & 0.151 & 0.154 & 0.152 & 0.155 \\
\hline
\end{tabular}

Note: *,**, **: Coefficient different from zero at $10 \%, 5 \%, 1 \%$ significance levels, respectively.

Robust standard errors are in parentheses. 
Table 3

Happiness functions of only "born” urban residents

Dependent variable: cardinal happiness scores; regression method: OLS

\begin{tabular}{llllll}
\hline & $(9)$ & $(10)$ & $(11)$ & $(12)$ & $(13)$ \\
\hline BI & 0.121 & -0.0565 & $-0.163^{*}$ & 0.174 & -0.0711 \\
Gini & $(0.123)$ & $(0.0430)$ & $(0.0956)$ & $(0.436)$ & $(0.0438)$ \\
& $3.660^{* * *}$ & $3.658^{* * *}$ & $3.691^{* * *}$ & $3.652^{* * *}$ & $3.696^{* * *}$ \\
Age $\times$ BI & $(0.627)$ & $(0.626)$ & $(0.627)$ & $(0.627)$ & $(0.627)$ \\
& $-0.00463^{*}$ & & & & \\
Party member $\times$ BI & $(0.00253)$ & & & & \\
& & $-0.108^{*}$ & & & \\
Years of schooling completed $\times$ BI & & $(0.0573)$ & & & \\
& & & 0.00653 & & -0.0484 \\
Log household income per capita $\times$ BI & & & $(0.00774)$ & & \\
& & & & & \\
Male $\times$ BI & & & & & \\
& & & & & \\
Other controls & & & & & \\
Number of observations & Yes & Yes & Yes & Yes & \\
R-squared & 2942 & 2942 & 2942 & 2942 & 2942 \\
\hline
\end{tabular}

Note: *,**, ***: Coefficient different from zero at $10 \%, 5 \%, 1 \%$ significance levels, respectively.

Robust standard errors are in parentheses. 


\section{Appendix Table 1}

City-level variable definitions and descriptions

\begin{tabular}{llrrrrr}
\hline Variable & Definitions & Obs. & Mean & s. d. & Min & Max \\
\hline BI & $\begin{array}{l}\text { Income ratio between } \\
\text { urban residents and }\end{array}$ & 26 & 1.9105 & 0.5283 & 1.1226 & 3.4750 \\
$\begin{array}{l}\text { migrants in a city } \\
\text { City-level } \\
\text { Gini }\end{array}$ & $\begin{array}{l}\text { Including urban } \\
\text { residents and migrants }\end{array}$ & 26 & 0.3459 & 0.0335 & 0.2868 & 0.4094 \\
\hline
\end{tabular}

Appendix Table 2

Decomposition of entropy index based on the hukou group

\begin{tabular}{lcccc}
\hline Index & $\begin{array}{l}\text { Total } \\
\text { inequality }\end{array}$ & $\begin{array}{l}\text { Within-group } \\
\text { inequality }\end{array}$ & $\begin{array}{l}\text { Between-group inequality } \\
(\mathrm{BI})\end{array}$ & $\begin{array}{l}\text { Between-group } \\
\text { inequality/total } \\
\text { inequality }\end{array}$ \\
\hline GE(0) & 0.2535 & 0.2067 & 0.0468 & $18.46 \%$ \\
$\begin{array}{l}\text { GE(1)- } \\
\text { Theil Index }\end{array}$ & 0.2376 & 0.1958 & 0.0418 & $17.59 \%$ \\
GE(2) & 0.2971 & 0.2590 & 0.0381 & $12.82 \%$ \\
\hline
\end{tabular}




\section{Appendix Table 3}

Personal characteristics variable definitions and descriptions

\begin{tabular}{|c|c|c|c|c|c|c|c|c|c|}
\hline \multirow{2}{*}{\multicolumn{2}{|c|}{ Variable }} & \multirow[t]{2}{*}{ Definitions } & \multicolumn{2}{|c|}{$\begin{array}{l}\text { Full sample } \\
5630\end{array}$} & \multicolumn{2}{|c|}{$\begin{array}{l}\text { Urban residents } \\
3797\end{array}$} & \multicolumn{2}{|c|}{$\begin{array}{l}\text { Migrants } \\
1833\end{array}$} & \multirow{2}{*}{$\begin{array}{l}\text { ANOVA test } \\
\mathrm{p} \text { value }\end{array}$} \\
\hline & & & Mean & s. d. & Mean & s. d. & Mean & s. d. & \\
\hline \multicolumn{2}{|l|}{ Happiness } & $\begin{array}{l}\text { Cardinal } \\
\text { happiness scores }\end{array}$ & 2.451 & 0.846 & 2.491 & 0.859 & 2.368 & 0.811 & 0.0000 \\
\hline \multicolumn{2}{|l|}{ Male } & $\begin{array}{l}\text { Dummy variable, } \\
\text { male }=1\end{array}$ & 0.479 & 0.500 & 0.416 & 0.493 & 0.610 & 0.488 & 0.0000 \\
\hline \multicolumn{2}{|l|}{ Age } & & 43.31 & 11.73 & 47.19 & 10.89 & 35.29 & 9.02 & 0.0000 \\
\hline \multirow[t]{3}{*}{ Marital status: } & Married & $\begin{array}{l}\text { Dummy variable, } \\
\text { married = } 1\end{array}$ & 0.925 & 0.263 & 0.934 & 0.248 & 0.906 & 0.292 & 0.0000 \\
\hline & Divorced & $\begin{array}{l}\text { Dummy variable, } \\
\text { divorced = } 1\end{array}$ & 0.014 & 0.116 & 0.015 & 0.123 & 0.010 & 0.101 & 0.0629 \\
\hline & Widowed & $\begin{array}{l}\text { Dummy variable, } \\
\text { widowed = } 1\end{array}$ & 0.020 & 0.141 & 0.027 & 0.163 & 0.006 & 0.077 & 0.0000 \\
\hline \multicolumn{2}{|c|}{ Years of education } & & 10.05 & 3.31 & 11.05 & 3.08 & 7.97 & 2.76 & 0.0000 \\
\hline \multicolumn{2}{|l|}{ Unemployed } & $\begin{array}{l}\text { Dummy variable, } \\
\text { unemployed = } 1\end{array}$ & 0.034 & 0.181 & 0.044 & 0.206 & 0.013 & 0.111 & 0.0000 \\
\hline \multicolumn{2}{|c|}{$\begin{array}{l}\text { Household income per } \\
\text { capita }\end{array}$} & $\begin{array}{l}\text { Per capita } \\
\text { household yearly } \\
\text { income }\end{array}$ & 7634.78 & 5902.97 & 9119.12 & 5885.85 & 4560.01 & 4610.48 & 0.0000 \\
\hline \multicolumn{2}{|c|}{$\begin{array}{l}\text { Communist Party } \\
\text { member }\end{array}$} & $\begin{array}{l}\text { Dummy variable, } \\
\text { Communist Party } \\
\text { member = } 1\end{array}$ & 0.235 & 0.424 & 0.332 & 0.471 & 0.035 & 0.185 & 0.0000 \\
\hline \multicolumn{2}{|c|}{$\begin{array}{l}\text { House square meters per } \\
\text { capita }\end{array}$} & & 14.28 & 9.59 & 17.17 & 8.37 & 8.29 & 9.16 & 0.0000 \\
\hline \multicolumn{2}{|c|}{$\begin{array}{l}\text { Expect big income } \\
\text { increase }\end{array}$} & $\begin{array}{l}\text { Dummy variable, } \\
\text { expect big income } \\
\text { increase }=1\end{array}$ & 0.036 & 0.187 & 0.020 & 0.140 & 0.070 & 0.256 & 0.0000 \\
\hline \multicolumn{2}{|c|}{$\begin{array}{l}\text { Expect small income } \\
\text { increase }\end{array}$} & $\begin{array}{l}\text { Dummy variable, } \\
\text { expect small } \\
\text { income increase = } \\
1\end{array}$ & 0.477 & 0.500 & 0.441 & 0.497 & 0.552 & 0.497 & 0.0000 \\
\hline \multicolumn{2}{|c|}{ Expect income decrease } & $\begin{array}{l}\text { Dummy variable, } \\
\text { expect income } \\
\text { decrease }=1\end{array}$ & 0.165 & 0.371 & 0.200 & 0.400 & 0.093 & 0.291 & 0.0000 \\
\hline \multirow[t]{2}{*}{ Health: } & Good & $\begin{array}{l}\text { Dummy variable, } \\
\text { good Health = } 1\end{array}$ & 0.695 & 0.460 & 0.593 & 0.491 & 0.908 & 0.289 & 0.0000 \\
\hline & Bad & $\begin{array}{l}\text { Dummy variable, } \\
\text { good Bad = } 1\end{array}$ & 0.0517 & 0.221 & 0.067 & 0.250 & 0.020 & 0.139 & 0.0000 \\
\hline
\end{tabular}

Data Sources: CHIPS2002 